\title{
The quality of life in Chinese population with chronic non- communicable diseases according to EQ-5D-3L: a systematic review
}

\author{
Ting Zhou ${ }^{1} \cdot$ Haijing Guan ${ }^{2,3} \cdot$ Jiaqi Yao ${ }^{1} \cdot$ Xiaomo Xiong $^{1} \cdot$ Aixia Ma $^{1}$ (i)
}

Accepted: 26 June 2018 / Published online: 6 July 2018

(c) The Author(s) 2018

\begin{abstract}
Purpose Over the past decade, a changing spectrum of disease has turned chronic non-communicable diseases (CNCDs) into the leading cause of death worldwide. During the 2015 in China, there were more than 6.6 million deaths from NCDs, which was the highest rate around the world. In the present study, we performed a systematic review to analyze the healthrelated quality of life (HRQoL) according to EQ-5D-3L instrument in patients with different kinds of CNCDs in China.

Methods We searched PubMed, Embase, Web of Science, Cochrane Library, VIP, WanFang Data, and CNKI databases up to April 12, 2018, to identify all relevant studies that reported on HRQoL assessed by EQ-5D-3L instrument in Chinese patients with CNCDs. Expert consultation and hand-searching of reference lists from retrieved studies were employed to identify additional references. The variation of mean utility values, EQ-VAS score ranges, and responses for each EQ-5D dimension described in relevant studies were extracted.

Results A total of 5027 English-language articles and 618 Chinese-language articles were identified, among which 38 articles met full inclusion criteria. These 38 studies involved 18 kinds of CNCDs. In this review, the health utility for diabetes mellitus ranged from 0.79 to 0.94 (EQ-5D VAS scores from 61.5 to 78.6), hypertension from 0.78 to 0.93 (70.1-77.4), coronary heart disease from 0.75 to 0.90 (71.0-77.0), chronic obstructive pulmonary disease from 0.64 to 0.80 (55.0-67.0), epilepsy from 0.83 to 0.87 (78.3-79.6), cerebral infarction from 0.51 to 0.75 (49.7-79.0), while children cerebral palsy was 0.44 (27.3).

Conclusions EQ-5D-3L is widely used in studies of HRQoL associated with CNCDs in China. Our results suggest that many factors may influence the measurement results of health utilities, including age, gender, sample source, comorbidities, rural/ urban, and EQ-5D-3L value sets.
\end{abstract}

Keywords Quality of life · Chronic non-communicable diseases · EQ-5D-3L · Chinese population

\section{Introduction}

There are more than 1.3 billion people in China, which make almost $1 / 6$ of world's population, and largely contribute to a global patients' community. During the 2015 in China, there were more than 6.6 million deaths from non-communicable

Ting Zhou and Haijing Guan are first authors.

Aixia Ma

aixiaxa1961@163.com

Ting Zhou

zhouting20150301@163.com

Haijing Guan

guanhaijing_1@163.com

Jiaqi Yao

957661551@qq.com

Xiaomo Xiong

xiongxiaomo_cpu@126.com
1 School of International Pharmaceutical Business, China Pharmaceutical University, No. 639 Longmian Avenue, Jiangning District, Nanjing 211198, Jiangsu, China

2 China Center for Health Economic Research, Peking University, Beijing, China

3 School of Pharmaceutical Sciences, Peking University, Beijing, China 
diseases (NCDs), which was the highest rate around the world [1]. Over the past decade, diseases such as diabetes mellitus (DM), coronary heart disease (CHD), chronic obstructive pulmonary disease (COPD), and hypertension have become the most common chronic diseases. China is the home to largest number of DM patients worldwide. It is estimated that there are currently 109.6 million adults living with DM, while in 2015 there were 1.3 million deaths caused by DM [2]. Furthermore, the economic burden of DM is substantial. In China, healthcare expenditures related to diabetes were 51 billion dollars in 2015, and they are expected to increase to 72 billion dollars by 2040 [2]. According to the fifth national health services survey in China, currently there are approximately 10.2 thousand CHD patients per million people [3], which is an increase of $34.5 \%$ in number of patients from 2008 [4]. COPD is characterized by chronic airflow limitation. It is a progressive lung disease and a leading cause of global death [5]. In China, the prevalence of COPD varies from 5 to $13 \%$ [6]. More than one billion people worldwide are diagnosed with hypertension, which is a NCD that causes stroke, heart disease, and kidney failure [7]. The hypertension prevalence rate is $14.3 \%$ among the population aged over 35 years or older in China [3]. The burden of disease among the aging population has become more serious than ever. In China, there are more than 0.23 billion people aged over 60 , which accounted for $16.7 \%$ of the total population in 2016 [8]. The number of elderly people has increased by $29.5 \%$ since 2010 [9].

Following the shift from biomedicine model to the biopsycho-social medical model [10], people have gained a deeper health awareness. Nowadays, the health measurements evaluate the life expectancy, as well as the quality of life (QoL). WHO has defined QoL as "the individual's perception of their position in life in the context of the culture and value systems in which they live and in relation to their goals" [11]. The concept of health-related quality of life (HRQoL) can be interpreted as an indicator of individual's well-being, and as effective pointer of potential health gains that can be brought on by various interventions [12]. The plan for "Healthy China 2030" was approved by the Political Bureau of the Communist Party of China Central Committee in 2016. Health promotion is an important part of national development strategy, and will remain so for at least next 15 years. Meanwhile, the healthcare reform in China is ever more comprehensive, thus improving the HRQoL in the whole population is one of its most important goals.

Patients' health-related preferences have an important role for exploring their disease progression and survival, while health utility can be used to represent individual's preference for a particular health state, which is widely used in health-related research and cost-utility analysis [13]. There are several health utility generic instruments, which mainly include the EuroQol 5-Dimensions (EQ-5D) [14], Health
Utilities Index (HUI) [15], and Short Form-6 Dimensions (SF-6D) [16] questionnaires. The three-level version EQ-5D questionnaire (EQ-5D-3L) was introduced by EuroQol Group in 1990. EQ-5D-3L has been recommended by both the UK National Institute of Health and Care Excellence (NICE) and China Guidelines for Pharmacoeconomic Evaluations (2011 edition) as a preferred outcome measure tool [17, 18].

EQ-5D-3L comprises five dimensions, including "Mobility," "Self-Care," "Usual Activities," "Pain/Discomfort," and "Anxiety/Depression." The questionnaire is divided in dimensions, and each dimension has three levels: "have no problems/be not," "have some/moderate problems," "have extremely problems/unable to." Therefore, $3 \mathrm{~L}$ questionnaire can be used to define 243 kinds of different health states [19]. Based on a value set, we can convert EQ-5D states to a single summary index, namely health utility, which can be used to calculate the Quality-adjusted life years (QALYs). The estimation of EQ-5D-3L value set is based on local people's health preference and is affected by culture, social environment, as well as economic development. Thus, it is necessary to derive country-specific value set for EQ-5D health states. Since 1997, EQ-5D-3L value sets have been estimated by more than 20 countries (China, UK, USA, Korea, Japan, etc.). The questionnaire is currently translated into more than 170 languages, and is widely applied with good reliability and validity in both disease population (diabetes mellitus, hypertension, coronary heart disease, chronic obstructive pneumonia disease, etc.) and general population [20-23].

Due to the rising burden of diseases, it is necessary to pay more attention to HRQoL [24]. HRQoL can reveal the comprehensive survival state of a patient, and thus can provide more evidence for decision-makers, especially for chronic non-communicable diseases (CNCDs). In recent years, $3 \mathrm{~L}$ questionnaire has been widely used in Chinese population with CNCDs to measure HRQoL. However, there is a lack of systematic reviews of these studies. The objective of the present review was to identify the kind of CNCD in China that EQ-5D-3L is mostly used for, as well as the variation of health utilities in different studies involving a specific CNCD.

\section{Methods}

\section{Search strategy and selection criteria}

We performed a systematic review according to the Preferred Reporting Items for Systematic Reviews and Meta-Analyses (PRISMA) guidelines [25]. All relevant studies that reported HRQoL evaluated by EQ-5D-3L questionnaire in Chinese patients with CNCDs were searched in PubMed, Embase, Web of Science, Cochrane Library, VIP, WanFang Data, and CNKI databases up to April 12, 2018. Search terms included "quality of life," "QoL," "HRQoL," "EQ-5D," "EuroQol," 
"five dimension," "China," "Chinese," "Randomized Controlled Trial," "RCT," "diseases," and "chronic non-communicable," and they were combined using Boolean logic (details in Appendix Table 3). Expert consultation and hand-searching of reference lists from retrieved studies were employed to identify additional references. VIP, WanFang Data, and CNKI are the most commonly used Chinese databases, which covers more than $95 \%$ of Chinese literatures, including journal articles, doctoral dissertations, masters' theses, conference papers, reference works, newspapers, patents, and laws.

Following the inclusion criteria, all the studies were cross-sectional researches in Chinese population with CNCDs that were conducted in China, that reported EQ5D-3L scores about a specific CNCDs with or without comorbidity by applying a value set, and that were full-text available. In this review, CNCDs are defined as "Diseases or conditions that occur in, or are known to affect, individuals over an extensive period of time and for which there are no known causative agents that are transmitted from one affected individual to another." [26], such as cancer, DM, and COPD. We also included studies where health utility was generated from different country's value set in the same sample. Languages were restricted to English and Chinese. We excluded any study if it was a review, or an abstract that used general population, communicable disease population, non-Chinese population, or Chinese subjects who did not live in China; that was longitudinal survey, intervention effect evaluation; where the only multiple diseases synthetic utility value was reported or there was no utility; and that was unrelated to HRQoL.

\section{Data collection and quality assessment}

Preliminary literature screening was performed by two authors independently based on the titles and abstracts. After title/abstract review, full-text articles were reviewed by two investigators to evaluate eligibility of studies for inclusion and to check the bibliography. Two researchers independently conducted data extraction from all included articles using a pre-formulated sheet. Publication details, data sources, sample size (gender), type of disease, mean age, comorbidities, EQ-5D health utilities, EQ-VAS scores, five-dimension results, full health ratio, and value set information were extracted. Disagreement was solved by a further discussion between reviewers. To extract more information, all the results were pooled into a customized sheet when different articles reported HRQoL from the same dataset.

We appraised methodological quality of each study using a 11-item cross-sectional study assessment checklist introduced by Agency for Health Research and Quality (AHRQ) [27]. Each item was assigned one response option from three alternative choices, "Yes/No/Unclear," based on study description. "Yes" for any item equaled one point, while "No" or "Unclear" equaled zero points. AHRQ defined the quality level of each article, and was obtained by adding all the item scores. A total of $0-3$ points meant low quality, 4-7 points moderate quality, and over 7 points signified high quality.

\section{Statistical analysis}

The variations of mean utility values described in all studies were reported. Besides that, descriptive analysis of EQVAS score ranges and response for each EQ-5D dimension were undertook. We conducted all calculations using Microsoft Excel 2013.

\section{Results}

A total of 5027 English-language articles and 618 Chineselanguage articles were identified via seven databases, while six additional studies were included after expert consultation and manual review. After checking for duplicates, we screened 3227 papers to assess for eligibility. Among these, 38 articles met the inclusion criteria [28-65] (Fig. 1). In total, 18 English-language articles and 20 Chinese-language articles were included in the review analysis. All the included cross-sectional studies were conducted between October 2006 and December 2017 (Table 1). Besides three studies that included only male patients $[60,63,65]$, all the other studies included both male and female patients. The AHRQ checklist score ranged from 4 to 10 points, median score was 7 points, while mode was 7 (details in Appendix Table 4). There was no study of a low quality, while 29 studies were of median quality [29-31, 33-37, 39-42, $45-52,54,55,57-59,61,62,64,65]$ and 9 were of high quality $[28,32,38,43,44,53,56,60,63]$.

We extracted HRQoL data on 18 kinds of CNCDs based on EQ-5D-3L from the included studies (Table 2). The diseases were diabetes mellitus (DM), hypertension, coronary heart disease (CHD), chronic obstructive pneumonia disease (COPD), epilepsy, cerebral infarction (CI), stroke, chronic liver diseases (CLD), lung cancer (LC), esophagus cancer (EC), cerebral palsy (CP), rheumatoid arthritis (RA), sarcopenia, atrial fibrillation (AF), Kashin Beck disease (KBD), chronic prostatitis (CPT), visual impairment (VD), and hemophilia.

\section{Diabetes mellitus}

In this review, ten studies reported health utilities for diabetes mellitus [28-37]. The extreme values as well as the utility values that ranged from 0.79 to 0.94 were calculated 
Fig. 1 Flow diagram of article selection for inclusion

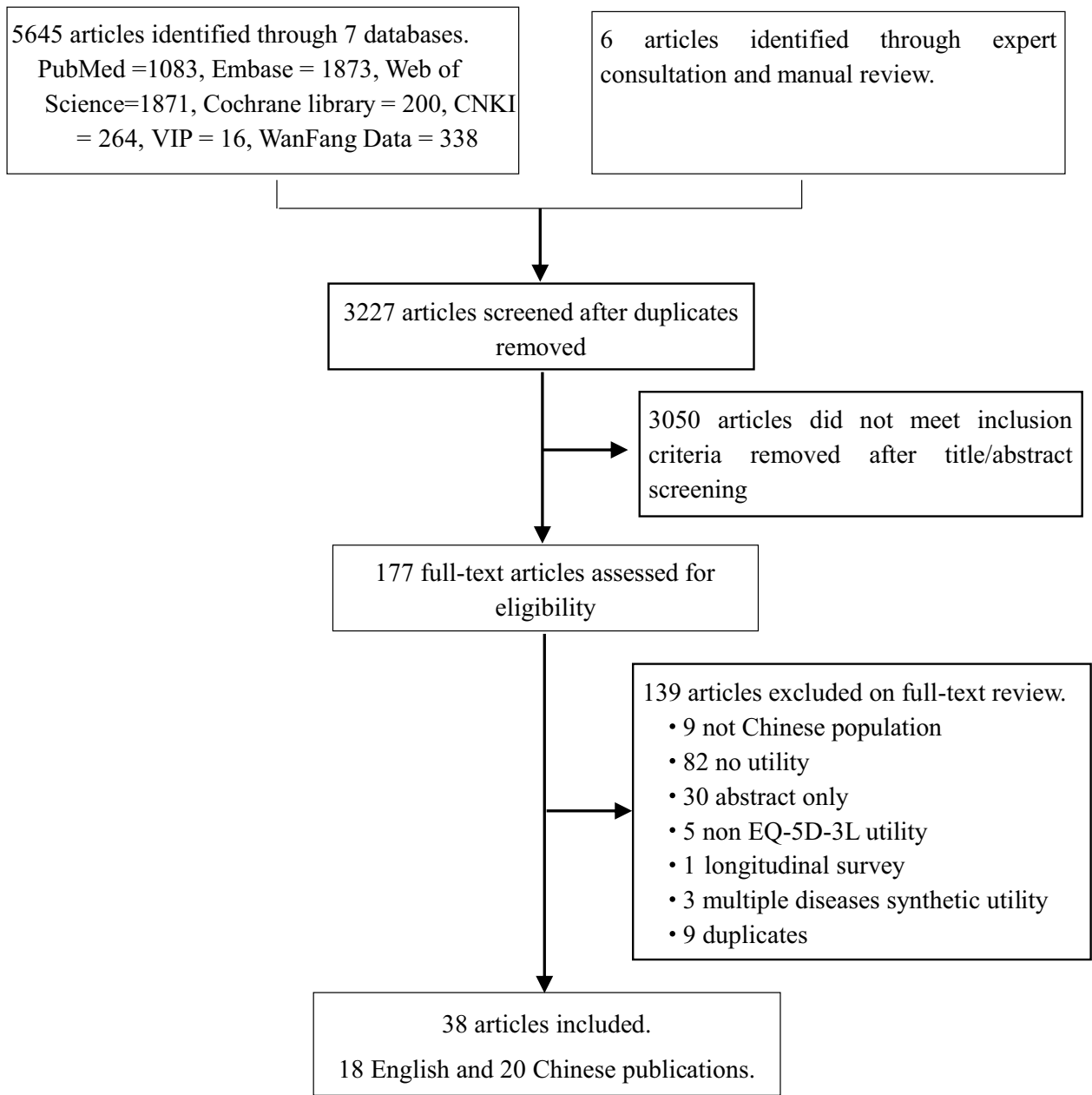

by Japanese value set. However, the study with the highest values [37] was conducted in rural communities and reported a younger mean age (57.2 vs. 63.2 years) without any comorbidity compared to the study that was conducted at a hospital and that described a few serious T2DM comorbidities (hyperlipidemia, cardiovascular disease, and hypertension) with the lowest value [30]. Interestingly, when applied in Chinese value set, the results from Tang's study that included about 415 T2DM patients was 0.84 [31]. The EQ-5D VAS scores were from 61.5 to 78.6 in four studies [28, 29, 31, 32]. The decrease of health utility in DM patients was mainly caused by problems related to "Pain/ Discomfort" and "Anxiety/Depression" dimensions. Hypertension, hyperlipemia, and CHD were the most common DM comorbidities reported by the studies, and the prevalence of DM comorbidities was from 42.6 to $81.5 \%$, thus having a significant influence on HRQoL.

\section{Hypertension}

For the patients with hypertension, the utility values ranged from 0.78 to 0.93 in six studies [36, 37, 47-51]. Japanese value set and UK value set were applied in the hypertension disease population in the studies that reported the highest value [37] and the lowest value [48], respectively. We found that the study [37] with the highest value reported a younger mean age without any comorbidity compared to the study [48] on patients with hypertension and comorbidities. The EQ-5D VAS scores were from 70.1 to 77.4 in three studies [48-50]. "Pain/Discomfort" was the dimension with the most problems reported by the patients in three studies [37, $49,50]$.

\section{Coronary heart disease}

For the patients with CHD, the utility values ranged from 0.75 to 0.90 in five studies [37-41]. Two of them were about chronic stable angina (CSA) patients, which was a subgroup of CHD [40, 41]. The extreme values were generated by UK [41] (0.75) and Japanese value set [37] (0.90), respectively. In general, the mean age of CHD patients with highest utility was 57.2 years old and 68.1 years for those with the lowest utility. Moreover, the former was concerned with CHD patients without comorbidity in rural areas [41], 
Table 1 Basic characteristics of included studies

\begin{tabular}{|c|c|c|c|c|c|c|c|}
\hline & Survey time & Location & Patients & Male $(\%)$ & Disease & $\begin{array}{l}\text { Mean age (SD), } \\
\text { years }\end{array}$ & $\begin{array}{l}\text { AHRQ } \\
\text { score }\end{array}$ \\
\hline Zhu [28] & 2010 & 23 provinces & 9650 & 51.0 & T2DM & $60.1(11.7)$ & 8 \\
\hline Liang [29] & $\begin{array}{l}\text { December } 2010 \text { to Janu- } \\
\text { ary } 2012\end{array}$ & Beijing city & 516 & 45.9 & $\mathrm{~T} 2 \mathrm{DM}$ & 62.3 & 5 \\
\hline Luo et al. [30] & July to October 2008 & Nanjing city & 256 & 50.4 & T2DM & $63.2(9.9)$ & 6 \\
\hline Tang et al. [31] & $\begin{array}{l}\text { March } 2014 \text { to August } \\
2014\end{array}$ & Deqing county & 415 & 55.9 & $\mathrm{~T} 2 \mathrm{DM}$ & $57.2(16.6)$ & 5 \\
\hline Han et al. [32] & $\begin{array}{l}\text { December } 2008 \text { to July } \\
2009\end{array}$ & 9 cities & 7082 & 51.1 & T2DM & 59.6 & 8 \\
\hline Chang [33] & $\begin{array}{l}\text { October } 2006 \text { to June } \\
2007\end{array}$ & Taiwan & 498 & 45.8 & T2DM & $63.7(13.8)$ & 7 \\
\hline \multirow[t]{3}{*}{ Yan et al. [34] } & $\begin{array}{l}\text { November } 2007 \text { to July } \\
2012\end{array}$ & Hong Kong & 10,952 & 56.1 & T2DM Normal ABI & $58.2(11.3)$ & 7 \\
\hline & & & 1230 & 45.1 & $\begin{array}{l}\text { T2DM Borderline } \\
\text { ABI }\end{array}$ & $60.4(14.2)$ & \\
\hline & & & 590 & 47.1 & T2DM PAD & $68.3(13.3)$ & \\
\hline \multirow[t]{3}{*}{ Ji et al. [35] } & $\begin{array}{l}\text { October } 2011 \text { to March } \\
2012\end{array}$ & China & 998 & 49.6 & T2DM Normal BMI & 56.6 & 6 \\
\hline & & & 822 & 49.3 & $\begin{array}{l}\text { T2DM Overweight } \\
\text { BMI }\end{array}$ & 56.5 & \\
\hline & & & 212 & 33.0 & T2DM Obese BMI & 53.5 & \\
\hline \multirow[t]{4}{*}{ Zhu et al. [36] } & - & Ningbo city & 319 & - & Diabetes mellitus & $50.7(17.31)^{\mathrm{a}}$ & 4 \\
\hline & & & 1383 & - & Hypertension & & \\
\hline & & & 45 & - & COPD & & \\
\hline & & & 41 & - & Stroke & & \\
\hline \multirow[t]{4}{*}{ Cao et al. [37] } & August to October 2010 & Beijing city & 802 & 27.9 & Diabetes mellitus & $57.2(9.77)^{\mathrm{a}}$ & 5 \\
\hline & & & 3263 & 34.7 & Hypertension & & \\
\hline & & & 416 & 44.0 & Stroke & & \\
\hline & & & 1930 & 28.0 & $\begin{array}{l}\text { Coronary heart } \\
\text { disease }\end{array}$ & & \\
\hline Xiong et al. [38] & $\begin{array}{l}\text { August } 2007 \text { to January } \\
2010\end{array}$ & Nanchang city & 330 & 65.2 & $\begin{array}{l}\text { Coronary heart } \\
\text { disease }\end{array}$ & $65.4(10.8)$ & 8 \\
\hline Wang et al. [39] & August to October 2010 & Beijing city & 1928 & 29.4 & $\begin{array}{l}\text { Coronary heart } \\
\text { disease }\end{array}$ & $61.6(9.2)$ & 7 \\
\hline Wu et al. $[40,41]^{\mathrm{b}}$ & July to December 2011 & $\begin{array}{l}\text { Tianjing and } \\
\text { Chengdu city }\end{array}$ & 411 & 49.6 & $\begin{array}{l}\text { Chronic stable } \\
\text { angina }\end{array}$ & $68.1(11.4)$ & 7 \\
\hline Wu et al. [42] & March to June 2011 & $\begin{array}{l}\text { Beijing, Guangzhou, } \\
\text { Shanghai and } \\
\text { Chengdu city }\end{array}$ & 678 & 72.9 & COPD & $70.4(10.1)$ & 7 \\
\hline Chen et al. [43] & $\begin{array}{l}\text { September } 2010 \text { to May } \\
2011\end{array}$ & Hong Kong & 154 & 98.7 & COPD & $72.9(8.1)$ & 8 \\
\hline Ding et al. [44] & 2009 & China & 675 & 60.7 & COPD & $62.0(11.4)$ & 8 \\
\hline Gao et al. [45] & July to October 2012 & Wuhan city & 144 & 52.1 & Epilepsy & $33.1(13.0)$ & 6 \\
\hline Gao et al. [46] & July 2012 to January 2013 & Wuhan city & 220 & 53.6 & Epilepsy & $31.8(13.0)$ & 5 \\
\hline Li et al. [47] & 2011 to 2012 & $\begin{array}{l}\text { Hangzhou and } \\
\text { Beijing city }\end{array}$ & 1006 & - & Hypertension & - & 6 \\
\hline He et al. [48] & $\begin{array}{l}\text { December } 2011 \text { to Febru- } \\
\text { ary } 2012\end{array}$ & Beijing city & 606 & 38.8 & Hypertension & 65.9 & 4 \\
\hline Wang 2017 [49] & July to September 2017 & Lian-yungang city & 2125 & 43.2 & Hypertension & $59.5(9.2)$ & 7 \\
\hline Wang et al. [50] & $\begin{array}{l}\text { January to December } \\
2017\end{array}$ & Dalian city & 487 & 48.5 & Hypertension & $65.6(6.7)$ & 5 \\
\hline Zhang et al. [51] & 2014 & Shanghai city & 419 & 46.3 & Hypertension & - & 7 \\
\hline He et al. [52] & - & Baoji city & 123 & 58.5 & Cerebral infarction & $58.6(13.2)$ & 4 \\
\hline
\end{tabular}


Table 1 (continued)

\begin{tabular}{|c|c|c|c|c|c|c|c|}
\hline & Survey time & Location & Patients & Male $(\%)$ & Disease & $\begin{array}{l}\text { Mean age }(\mathrm{SD}), \\
\text { years }\end{array}$ & $\begin{array}{l}\text { AHRQ } \\
\text { score }\end{array}$ \\
\hline \multirow[t]{3}{*}{ Wei [53] } & \multirow[t]{3}{*}{$\begin{array}{l}\text { November } 2012 \text { to March } \\
2013\end{array}$} & \multirow[t]{3}{*}{$\begin{array}{l}\text { Guangxi Autono- } \\
\text { mous Region }\end{array}$} & 60 & 60.0 & $\begin{array}{l}\text { Cerebral infarction } \\
\text { DBP }\end{array}$ & $57.5(10.1)$ & \multirow[t]{3}{*}{10} \\
\hline & & & 94 & 66.0 & $\begin{array}{l}\text { Cerebral infarction } \\
\text { NDBP }\end{array}$ & $61.6(9.8)$ & \\
\hline & & & 99 & 67.7 & $\begin{array}{l}\text { Cerebral infarction } \\
\text { ADBP }\end{array}$ & $66.3(9.4)$ & \\
\hline \multirow[t]{4}{*}{ Che et al. [54] } & \multirow[t]{4}{*}{$\begin{array}{l}\text { December } 2012 \text { to June } \\
2013\end{array}$} & \multirow[t]{4}{*}{ Kunming city } & 91 & 84.6 & Compensated & $48(11.3)$ & \multirow[t]{4}{*}{6} \\
\hline & & & 198 & 77.8 & Decompensated & $49(11.8)$ & \\
\hline & & & 131 & 79.4 & $\mathrm{HCC}$ & $56(11.1)$ & \\
\hline & & & 100 & 75.0 & Liver failure & $44(12.3)$ & \\
\hline \multirow[t]{3}{*}{ Yu et al. [55] } & \multirow[t]{3}{*}{ August to October 2015} & \multirow[t]{3}{*}{ Beijing city } & 55 & 81.8 & Compensated & $50.9(1.6)$ & \multirow[t]{3}{*}{6} \\
\hline & & & 64 & 68.8 & Decompensated & $52.4(1.4)$ & \\
\hline & & & 45 & 77.8 & $\mathrm{HCC}$ & $58.4(1.7)$ & \\
\hline Chen [56] & $\begin{array}{l}\text { December } 2014 \text { to July } \\
2015\end{array}$ & Anhui province & 188 & 68.6 & Lung cancer & $26-85^{\mathrm{c}}$ & 8 \\
\hline Chen et al. [57] & $\begin{array}{l}\text { December } 2014 \text { to July } \\
2015\end{array}$ & Anhui province & 209 & 78.0 & Esophagus cancer & $43-89^{c}$ & 7 \\
\hline Cui [58] & 2008 & Heibei province & 340 & 63.8 & cerebral palsy & $7.8(2.3)$ & 6 \\
\hline $\mathrm{Gu}[59]$ & July 2008 to January 2009 & Shanghai city & 92 & 10.9 & $\begin{array}{l}\text { Rheumatoid } \\
\text { arthritis }\end{array}$ & $52.5(12.3)$ & 7 \\
\hline Jiang [60] & $\begin{array}{l}\text { September } 2015 \text { to Janu- } \\
\text { ary } 2016\end{array}$ & Shandong province & 42 & 100.0 & Sarcopenia & $68.7(8.0)$ & 9 \\
\hline Wang et al. [61] & $\begin{array}{l}\text { October } 2009 \text { to May } \\
2010\end{array}$ & Taiwan & 742 & 59.8 & Atrial fibrillation & $70.2(11.8)$ & 7 \\
\hline Farooq et al. [62] & June to December 2009 & Shaanxi province & 368 & 48.6 & Kashin beck disease & $56.9(10.1)$ & 6 \\
\hline Zhao et al. [63] & $\begin{array}{l}\text { December } 2008 \text { to March } \\
2009\end{array}$ & Kunming city & 268 & 100.0 & Chronic prostatitis & $33.2(8.0)$ & 9 \\
\hline Lin et al. [64] & January to May 2008 & Taipei city & 318 & 48.1 & Visual impairment & 74 & 7 \\
\hline Sun et al. [65] & $\begin{array}{l}\text { June } 2011 \text { to February } \\
2012\end{array}$ & China & 110 & 100.0 & Hemophilia & $30.4(7.8)$ & 6 \\
\hline
\end{tabular}

$S D$ standard deviation, $A H R Q$ agency for health research and quality, $T 2 D M$ type 2 diabetes mellitus, $A B I$ ankle-brachial index, $P A D$ peripheral arterial disease, $B M I$ body mass index, $C O P D$ chronic obstructive pulmonary disease, $D B P$ dipper blood pressure, $N D B P$ non-dipper blood pressure, $A D B P$ anti-dipper blood pressure, $H C C$ hepatocellular cancer, - not reported in excluded study

'Full sample' mean age and SD

${ }^{\mathrm{b}}$ Same sample applied two different value sets in two articles, respectively

${ }^{\mathrm{c}}$ Only reported age range

while the latter included more serious CSA patients with comorbidities at hospitals [36]. Chinese and UK values have been separately applied in the same CHD sample in a previous study by $\mathrm{Wu}$ et al. [30, 41], and health utility calculated by Chinese value set [40] (0.78) was a little bit higher compared to UK set [41] (0.75). In terms of EQ-5D VAS scores, they ranged from 71.2 to 77.5 in four studies [38-41]. "Pain/Discomfort" was the dimension with the most problems reported by CHD patients in two studies [36, 38], while "Usual Activities" in CSA patients [40, 41]. Prevalence of comorbid hypertension most commonly occurred among CHD patients, followed by DM [37].

\section{Chronic obstructive pneumonia disease}

The health utility values for COPD patients ranged from 0.64 to 0.80 in four studies [36, 42-44]. The lowest value was calculated by UK value set [43]; however, the study that reported highest value did not describe the value set applied [44]. Patients with the highest value had a younger mean age and better post-bronchodilator $\mathrm{FEV}_{1}$ of predicted than the lowest one. Two studies reported that EQ-5D VAS scores were 55.3 [43] and 66.6 [42], respectively. The decrease of health utility in COPD patients was mainly caused by problems in "Mobility" dimension that were only described in 


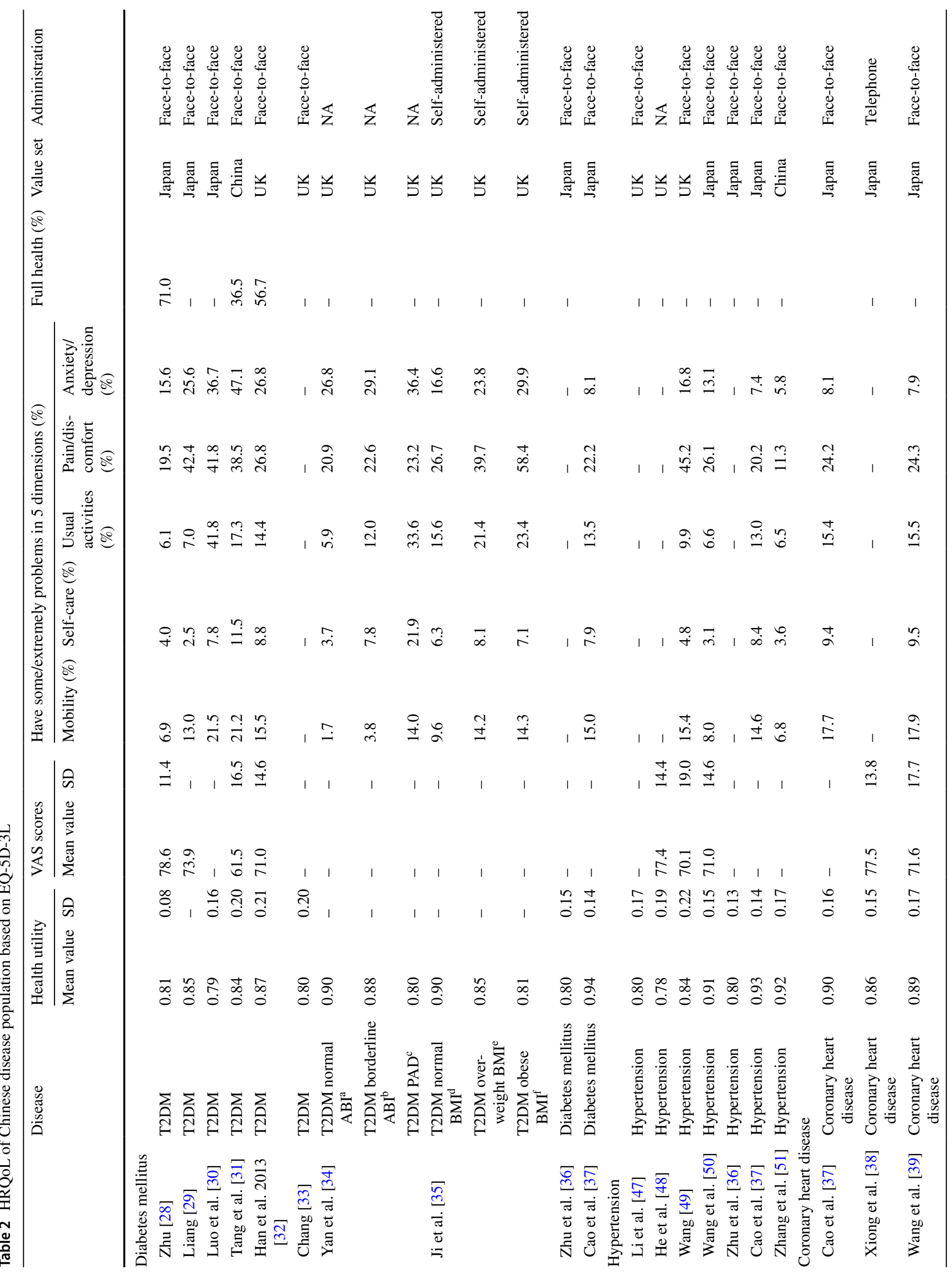




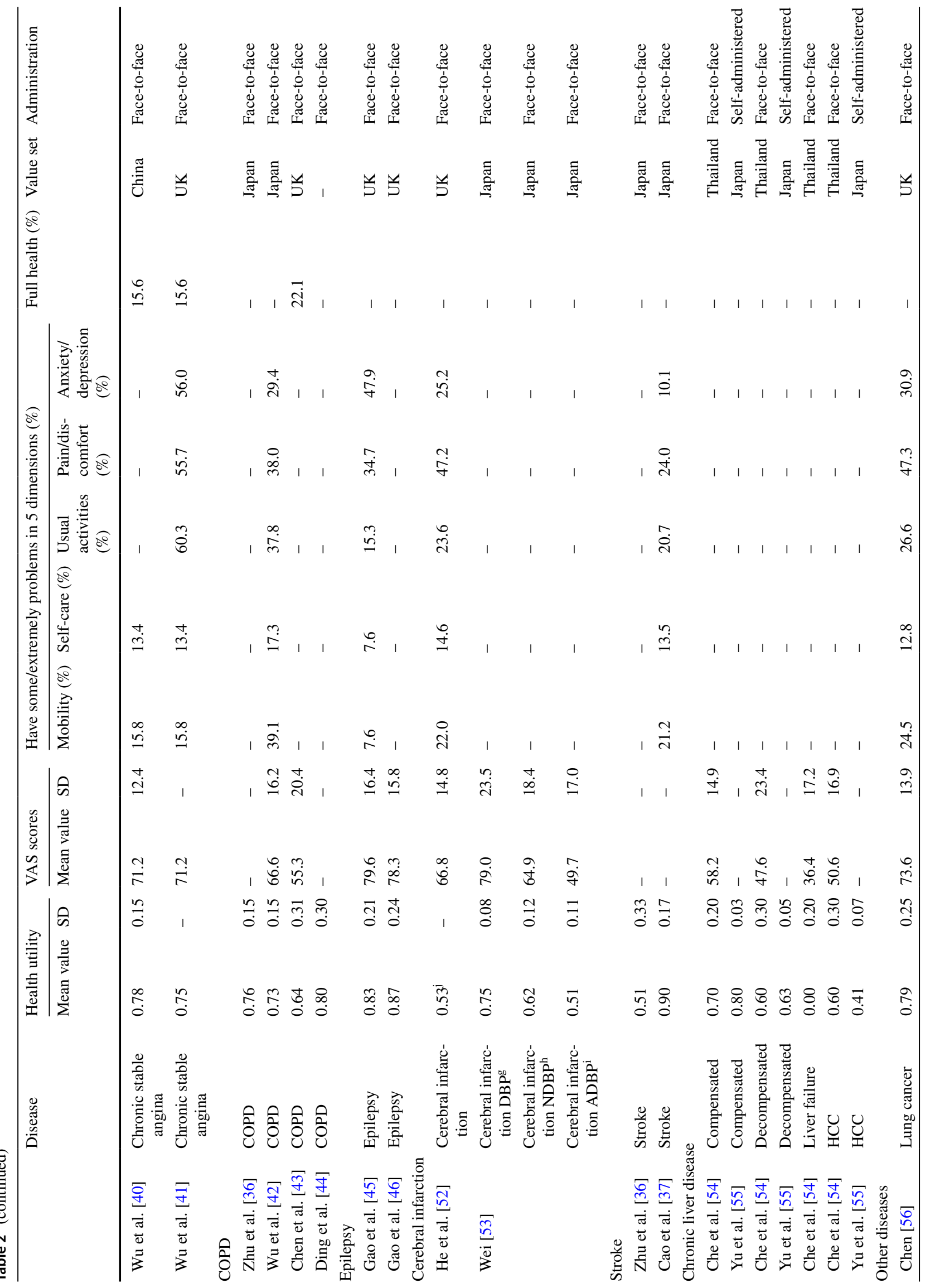




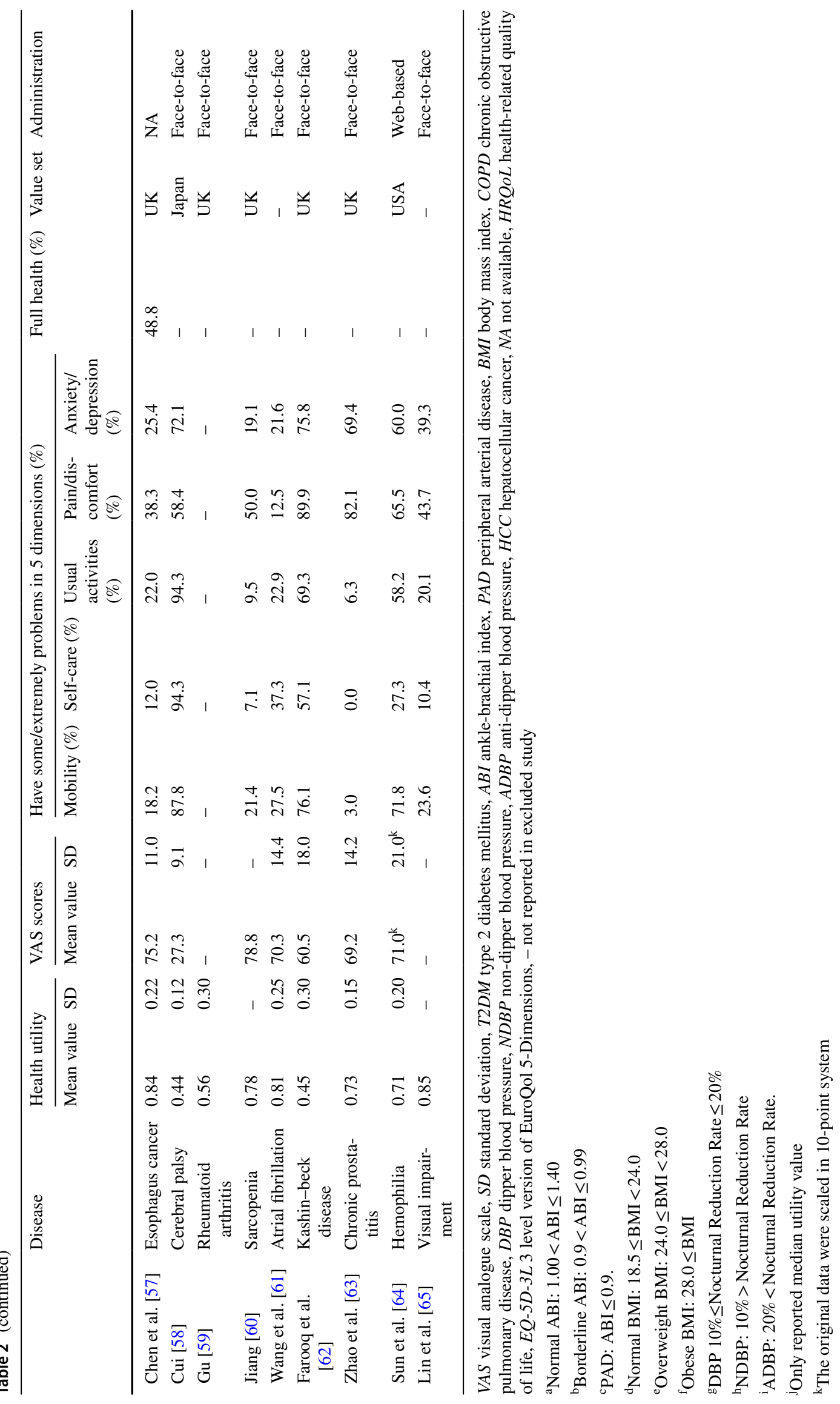


one study [42]. The prevalence of comorbidities in COPD patients was from 67.5 to $78.9 \%$ [42, 43].

\section{Epilepsy}

The health utility values for epilepsy patients ranged from 0.83 to 0.87 in two studies [45, 46], and both were calculated by UK value set. The patients in the study [46] that reported a higher utility were a little bit younger compared to patients in another study [45]. Besides that, it is possible that disease duration negatively affects the utility, since mean epilepsy duration of 8.5 years was reported in the study with lower value [45] compared to 6.0 years reported by another study [45]. EQ-5D VAS scores were 78.3 [46] and 79.6 [45], respectively. "Anxiety/Depression" was the most problematic dimension followed by "Pain/Discomfort" [45].

\section{Cerebral infarction}

In terms of health utility for patients with CI, two studies reported the HRQoL [52, 53]. Among these, one included three subgroup analyses based on different types of blood pressure [53]. The utility values and VAS scores were much lower in anti-dipper blood pressure group $(0.51 / 49.7)$ compared to dipper blood pressure group (0.75/79.0). The decrease of health utility in CI patients was mainly caused by problems in "Mobility" dimension [52].

\section{Stroke}

For the patients with stroke, the health utility ranged from 0.51 to 0.90 in two studies evaluated by Japanese value set $[36,37]$. The wide range of utility values for stroke was caused by the variation in mean age, comorbidities, and disease severity, etc. "Pain/Discomfort" was the dimension with most problems followed by "Mobility" [37]. No information was available on EQ-5D VAS score.

\section{Chronic liver disease}

The health utility values for patients with CLD differed in disease severity. The values ranged from 0.70 to 0.80 for compensated patients $[54,55]$, while it ranged from 0.60 to 0.63 for decompensated patients $[54,55]$. When the disease deteriorated to HCC, utility values were from 0.41 to $0.60[54,55]$, which was lower compared to compensated or decompensated patients. In addition, the health utilities of liver failure were 0.00 [54] which was equal to death. In terms of EQ-5D VAS scores, they ranged from 36.4 [54] (for liver failure) to 58.2 [54] (for compensated) in the study. There were no results on the most problematic dimension in CLD patients.

\section{Other diseases}

For the remaining ten diseases [56-65], i.e., lung cancer, sarcopenia, and hemophilia, the health utility value for each disease was only reported by one study.

Among the ten diseases, cerebral palsy was 0.44 [58] for the utility value which was the lowest one, while the highest one was 0.85 [64] in visually impaired patients. Japanese value set was applied in cerebral palsy patients. In terms of EQ-5D VAS scores, they ranged from 27.3 [58] (cerebral palsy) to 78.8 [60] (sarcopenia). "Pain/Discomfort" or "Anxiety/Depression" was the dimensions that caused most problems according to majority of studies.

\section{Discussion}

The present review focused on HRQoL in chronic non-communicable diseases in Chinese population. Over recent years, EQ-5D-3L questionnaire has been increasingly applied in different patient groups in China to measure their health utility values. Among 18 different types of diseases, DM, CHD, COPD, and hypertension are the most common CNCDs in China. Due to the high morbidity and mortality rates from these CNCDs, people have become more than ever concerned about the patients' state of survival and HRQoL.

Patient-reported outcomes are important to health decision-makers. As a generic instrument, EQ-5D can be easily used by patients to report their HRQoL. However, there are variations in health utility values for a specific $\mathrm{CNCD}$ among different studies. Given the level of heterogeneity is high regarding patient characteristics and study design, meta-analysis is not an appropriate method to calculate a single index across studies. The utility values of DM (0.79-0.94), CHD (0.75-0.90), COPD (0.64-0.80), hypertension (0.78-0.93), epilepsy (0.83-0.87), CI (0.51-0.75), stroke (0.51-0.90), and CLD (0.00-0.80) reflect HRQoL in patients with CNCDs and with different conditions in a QALY framework. The results can be changed by a series of factors, including age, gender, sample source, comorbidities, rural/urban, and value set. In general, the health status deteriorates as people get old. Thus, the utility value decreases with the increasing age. According to previous study, the values in patients with T2DM aged 60 and over (0.83) was lower compared to patients with T2DM who were younger than $60(0.86)$ [23].

In most of the studies that reported on gender-specific health utility values and were included in the present review [28-30, 38, 39, 48, 49, 56, 57] men had a better HRQoL compared to women, e.g., with reference to lung cancer, man had 0.81 , whereas woman had 0.76 value [56]. These results are in line with what has observed in the general population that men have a higher mean EQ-5D value score than women $[23,66]$. 
Besides gender, community-based or hospital-based cross-sectional surveys also have influence on the HRQoL assessment. It is logical to expect that patients in hospital will report more problems compared to stay at home patients. In line with previous statement, Chen et al. [43] conducted a survey to measure health utility in patients with COPD at hospital, while Zhu et al. [36] conducted the same survey in community, and the values have shown to lower in the former sample.

Comorbidity has an important role in the variation of health utility value. In addition to the number of comorbidities, different types of comorbidities can affect health utility values as well. Hypertension, DM, CHD, hyperlipidemia, and stroke are the most common comorbid conditions [28, 30, 36-38] The HRQoL in patients who do not have comorbidities with other diseases is better compared to the patients with comorbidities. Luo has reported that the value of utility in people only suffering DM was 0.86 ; however, it dropped to 0.69 when there were other comorbid conditions present [30]. Thus, the value of utility decreases in the presence of other comorbid diseases. In Liang's study [29], DM patients with one, two, or more than two kinds of comorbidities revealed the utility value of $0.86,0.83$, and 0.81 , respectively. Moreover, various comorbidities have different interaction effects on health utility. When patients have different kinds of comorbid conditions, HRQoL may change. According to Wang, patients with $\mathrm{CHD}$ and hypertension, and DM or stroke have the utility values of $0.89,0.87$, and 0.85 , respectively. Stroke is a serious comorbidity in many diseases [32, 37, 39, 67].

China is a country with dual economic structure between rural and urban areas [68] Due to the special economic structure, social policy and welfare are different for citizens living in city and countryside, and thus the medical service system and social insurance may have an impact on HRQoL. With reference to the impact of urban/rural context on HRQoL, it is still a matter of some controversy. Chen has reported that EC patients living in rural areas have a higher health utility value compared to those living in urban areas [57]. However, as regards to people with $\mathrm{LC}$, there has been no difference between rural and urban areas [56]. In China, most rural people are covered by "New Rural Cooperative Medical Insurance (NRCMI)," while urban people are covered by "Urban Residents Basic Medical Insurance (URBMI)" and "Urban Employee Basic Medical Insurance (UEBMI)." By the end of 2015, there were approximately 670 million, 377 million, 289 million people enrolled in NRCMI, URBMI, and UEBMI, respectively [69]. However, medical resources are distributed unequally, most of which are allocated in tertiary hospitals in urban areas. Furthermore, larger gap exists in terms of quality of medical services between urban and rural areas. Su et al. [70] compared the effects of NRCMI, URBMI, and UEBMI on HRQoL, and the results showed that the insured people of UEBMI had a higher mean EQ-5D utility score. Besides that, the horizontal inequality index suggested that there existed a higher pro-rich health inequity in NRCMI than urban schemes.

The application of value sets from various countries in the same disease population leads to different results in health utility values. In the same sample of patients with CHD [40], the values reported by Chinese value set were higher compared to UK value set [41]. The estimations of EQ-5D-3L value sets are based on local people's health preference and are affected by culture, social environment, and economic development. Furthermore, the preference in health might vary across different countries. Time trade-off is the most widely accepted method for estimating a EQ-5D-3L value set. Respondents are asked to imagine a certain health condition described by EQ-5D-3L that would be experienced for a fixed time (e.g., 10 years) and then to compare it with a shorter time in full health. Five countries' value sets (Japan [71], China [72], UK [73], Thailand [74], USA [75]) applied in the included studies are showed in Appendix Table 5. The best ill health state value is 0.961 with Chinese value set, higher than other four countries', which indicates the departure from full health declines less in health state value. "Pain/Discomfort" and "Anxiety/Depression" dimensions have a larger impact on disutility when applied in UK and USA value sets, while "Usual Activities" in Chinese value set. Chinese EQ-5D-3L value set has been estimated in 2014 [72], and it has shown to be the most appropriate set to use for exploration of the HRQoL in disease or general population in China.

EQ-5D-3L may lead to ceiling effects when measure HRQoL and health decrements may not be sensitive in disease population [76]. Five-level version (EQ-5D-5L) was introduced by EuroQol Group in 2005 [77] to reduce ceiling effects and improve the questionnaire's sensitivity to mild changes in health that cannot be capture by EQ5D-3L. Both the EQ-5D-3L and EQ-5D-5L comprise the same five dimensions, but EQ-5D-5L is added two more levels in each dimension: "have no problems/be not," "have slight problems/be slightly," "have some/moderate problems," "have severe problems/be severely," "have extremely problems/unable to." Therefore, EQ-5D-5L can define 3125 kinds of different health states. Although new version of EQ-5D questionnaire has some advantages over old version, EQ-5D-5L value sets have only been published since 2016. Chinese EQ-5D-5L value set has recently been estimated in 2017 [78]. The broad application of EQ-5D-5L countryspecific value sets are limited by the publication time. Most of researchers are unfamiliar with the new value sets. In view of this, when conducting a health economic assessment or population survey, researchers are still accustomed to using EQ-5D-3L to measure health utilities.

Compared with other countries' patients, the health utility of European people with T2DM was 0.69 and it was 0.65 in New Zealand and Australia [79, 80]. In general, the HRQoL of Chinese T2DM patients might be better 
than these countries' T2DM sufferers. A systematic review reported that the utility values of cardiovascular disease patients ranged from 0.24 to 0.90 [81], and the highest EQ$5 \mathrm{D}-3 \mathrm{~L}$ values were reported in people living with $\mathrm{CHD}$. For COPD patients, a meta-analysis reported the utility values were from 0.62 to 0.82 by severity of the disease [82], and the results were similar to COPD patients in China.

The main limitation of this review is number of studies reporting on each CNCD. Even though 18 different kinds of diseases were included, more than half of the CNCDs were reported separately. Due to the lack of sufficient information on health utility for some of the CNCDs discussed above, it is difficult to get accurate conclusions about the HRQoL in various Chinese population with CNCDs.

The comparison and analysis of HRQoL across different populations with CNCDs is of utmost importance. Utility value is a single index that reflects synthetic information about people's health, and that can provide useful evidence for decisionmakers upon optimizing the allocation of health resources.
Author contributions AXM, TZ, and HJG designed the review protocol. AXM and TZ conceived the literature strategies. TZ and HJG performed title/abstract review independently. TZ and JQY independently reviewed full-text articles and determined included articles. TZ and HJG extracted data. TZ and XMX assessed study quality using AHRQ checklists. TZ and HJG wrote the manuscript with contributions from AXM. All authors approved the final version.

\section{Compliance with ethical standards}

Conflict of interest The authors declare no competing interests.

Ethical approval All data in this review were based on previous published studies, and thus no ethical approval and patient consent are required.

Open Access This article is distributed under the terms of the Creative Commons Attribution 4.0 International License (http://creativeco mmons.org/licenses/by/4.0/), which permits unrestricted use, distribution, and reproduction in any medium, provided you give appropriate credit to the original author(s) and the source, provide a link to the Creative Commons license, and indicate if changes were made.
Table 3 Literature search strategies

\begin{tabular}{|c|c|c|c|c|c|}
\hline & \multirow[t]{2}{*}{ Search terms } & \multicolumn{4}{|l|}{ Databases } \\
\hline & & PubMed & Embase & Web of science & Cochrane library \\
\hline$\# 1$ & Quality of life & 218,659 & 385,677 & 388,562 & 75,309 \\
\hline \#2 & QoL & 30,551 & 56,702 & 28,499 & 10,349 \\
\hline \#3 & HRQoL & 12,774 & 20,084 & 12,350 & 3340 \\
\hline \#4 & $\# 1$ or \#2 or \#3 & 220,618 & 392,362 & 390,234 & 76,062 \\
\hline \#5 & eq- $5 d$ & 5825 & 10,988 & 6259 & 3390 \\
\hline \#6 & EuroQol & 4051 & 6057 & 4298 & 2277 \\
\hline$\# 7$ & Five dimension & 154 & 5058 & 26,161 & 628 \\
\hline \#8 & $\# 5$ or $\# 6$ or $\# 7$ & 7754 & 18,375 & 33,795 & 4533 \\
\hline$\# 9$ & $\# 4$ and \#8 & 5691 & 11,107 & 7616 & 3698 \\
\hline \#10 & China & 128,958 & 153,634 & 488,511 & 40,413 \\
\hline \#11 & Chinese & 170,044 & 221,032 & 326,135 & 49,739 \\
\hline$\# 12$ & $\# 10$ or \#11 & 267,060 & 335,522 & 733,456 & 71,681 \\
\hline$\# 13$ & $\# 9$ and \#12 & 140 & 273 & 220 & 284 \\
\hline \#14 & $\# 4$ and \#12 & 4284 & 7302 & 8980 & 5892 \\
\hline \#15 & $\# 8$ and \#12 & 195 & 444 & 1023 & 302 \\
\hline \#16 & $\# 14$ or $\# 15$ & 4339 & 7473 & 9783 & 5903 \\
\hline \#17 & $\mathrm{RCT}$ & 16,672 & 27,771 & 16,305 & 512,063 \\
\hline \#18 & Randomized controlled trial & 53,410 & 295,111 & 387,155 & 628,242 \\
\hline \#19 & Clinical trial & 118,324 & 326,333 & 582,836 & 688,438 \\
\hline \#20 & $\# 17$ or \#18 or \#19 & 177,958 & 502,861 & 806,195 & 983,165 \\
\hline \#21 & \#14 not \#20 & 3887 & 6313 & 7325 & 491 \\
\hline \#22 & $\# 15$ not \#20 & 183 & 418 & 980 & 9 \\
\hline \#23 & $\# 13$ not \#20 & 136 & 257 & 194 & 10 \\
\hline$\# 24$ & $\# 21$ or \# 22 & 3937 & 6474 & 8111 & 491 \\
\hline$\# 25$ & Disease & $2,696,747$ & $3,686,979$ & $3,592,538$ & 266,098 \\
\hline \#26 & Chronic non-communicable & 566 & 729 & 1390 & 136 \\
\hline$\# 27$ & $\# 25$ or \#26 & $2,697,028$ & $3,687,355$ & $3,592,546$ & 266,115 \\
\hline \#28 & $\# 16$ and \#27 & 1189 & 2177 & 2489 & 3537 \\
\hline \#29 & \#24 and \#27 & 1083 & 1873 & 1871 & 200 \\
\hline
\end{tabular}


Table 4 AHRQ checklist scoring

\begin{tabular}{|c|c|c|c|c|c|c|c|c|c|c|c|c|}
\hline & 1 & 2 & 3 & 4 & 5 & 6 & 7 & 8 & 9 & 10 & 11 & Scores \\
\hline Zhu [28] & Y & $\mathrm{Y}$ & $\mathrm{Y}$ & UC & $\mathrm{N}$ & $\mathrm{Y}$ & $\mathrm{Y}$ & $\mathrm{Y}$ & $\mathrm{Y}$ & $\mathrm{Y}$ & UC & 8 \\
\hline Liang [29] & $\mathrm{Y}$ & $\mathrm{Y}$ & $\mathrm{Y}$ & UC & $\mathrm{N}$ & $\mathrm{Y}$ & $\mathrm{N}$ & $\mathrm{Y}$ & $\mathrm{N}$ & $\mathrm{N}$ & UC & 5 \\
\hline Luo et al. [30] & $\mathrm{Y}$ & $\mathrm{Y}$ & $\mathrm{Y}$ & $\mathrm{Y}$ & $\mathrm{N}$ & $\mathrm{Y}$ & $\mathrm{N}$ & $\mathrm{Y}$ & $\mathrm{N}$ & $\mathrm{N}$ & UC & 6 \\
\hline Tang et al. [31] & $\mathrm{Y}$ & $\mathrm{Y}$ & $\mathrm{Y}$ & UC & $\mathrm{N}$ & $\mathrm{Y}$ & $\mathrm{N}$ & $\mathrm{Y}$ & $\mathrm{N}$ & $\mathrm{N}$ & UC & 5 \\
\hline Han et al. [32] & $\mathrm{Y}$ & $\mathrm{Y}$ & $\mathrm{Y}$ & $\mathrm{Y}$ & $\mathrm{Y}$ & $\mathrm{Y}$ & $\mathrm{N}$ & $\mathrm{Y}$ & $\mathrm{N}$ & $\mathrm{Y}$ & UC & 8 \\
\hline Chang [33] & $\mathrm{Y}$ & $\mathrm{Y}$ & $\mathrm{Y}$ & $\mathrm{N}$ & $\mathrm{Y}$ & $\mathrm{N}$ & $\mathrm{Y}$ & $\mathrm{Y}$ & $\mathrm{N}$ & $\mathrm{Y}$ & UC & 7 \\
\hline Yan et al. [34] & $\mathrm{Y}$ & $\mathrm{Y}$ & $\mathrm{Y}$ & UC & $\mathrm{Y}$ & $\mathrm{N}$ & $\mathrm{Y}$ & $\mathrm{Y}$ & $\mathrm{N}$ & $\mathrm{Y}$ & UC & 7 \\
\hline Ji et al. [35] & $\mathrm{Y}$ & $\mathrm{Y}$ & $\mathrm{Y}$ & UC & $\mathrm{N}$ & $\mathrm{Y}$ & $\mathrm{Y}$ & $\mathrm{N}$ & $\mathrm{Y}$ & $\mathrm{N}$ & UC & 6 \\
\hline Zhu et al. [36] & $\mathrm{Y}$ & $\mathrm{Y}$ & $\mathrm{N}$ & $\mathrm{UC}$ & $\mathrm{N}$ & $\mathrm{Y}$ & $\mathrm{N}$ & $\mathrm{Y}$ & $\mathrm{N}$ & $\mathrm{N}$ & UC & 4 \\
\hline Cao et al. [37] & $\mathrm{Y}$ & $\mathrm{Y}$ & $\mathrm{Y}$ & $\mathrm{UC}$ & $\mathrm{N}$ & $\mathrm{Y}$ & $\mathrm{N}$ & $\mathrm{Y}$ & $\mathrm{N}$ & $\mathrm{N}$ & UC & 5 \\
\hline Xiong et al. [38] & $\mathrm{Y}$ & $\mathrm{Y}$ & $\mathrm{Y}$ & $\mathrm{Y}$ & $\mathrm{N}$ & $\mathrm{Y}$ & $\mathrm{N}$ & $\mathrm{Y}$ & $\mathrm{Y}$ & $\mathrm{N}$ & $\mathrm{Y}$ & 8 \\
\hline Wang et al. [39] & $\mathrm{Y}$ & $\mathrm{Y}$ & $\mathrm{Y}$ & $\mathrm{UC}$ & $\mathrm{Y}$ & $\mathrm{Y}$ & $\mathrm{N}$ & $\mathrm{Y}$ & $\mathrm{N}$ & $\mathrm{Y}$ & UC & 7 \\
\hline Wu et al. [40] & $\mathrm{Y}$ & $\mathrm{Y}$ & $\mathrm{Y}$ & $\mathrm{UC}$ & $\mathrm{Y}$ & $\mathrm{Y}$ & $\mathrm{N}$ & $\mathrm{Y}$ & $\mathrm{N}$ & $\mathrm{Y}$ & UC & 7 \\
\hline Wu et al. [41] & $\mathrm{Y}$ & $\mathrm{Y}$ & $\mathrm{Y}$ & UC & $\mathrm{N}$ & $\mathrm{Y}$ & $\mathrm{Y}$ & $\mathrm{Y}$ & $\mathrm{N}$ & $\mathrm{Y}$ & UC & 7 \\
\hline Wu et al. [42] & $\mathrm{Y}$ & $\mathrm{Y}$ & $\mathrm{Y}$ & $\mathrm{Y}$ & $\mathrm{N}$ & $\mathrm{Y}$ & $\mathrm{N}$ & $\mathrm{Y}$ & $\mathrm{N}$ & $\mathrm{Y}$ & UC & 7 \\
\hline Chen et al. [43] & $\mathrm{Y}$ & $\mathrm{Y}$ & $\mathrm{Y}$ & $\mathrm{Y}$ & $\mathrm{N}$ & $\mathrm{Y}$ & $\mathrm{Y}$ & $\mathrm{Y}$ & $\mathrm{N}$ & $\mathrm{Y}$ & UC & 8 \\
\hline Ding et al. [44] & $\mathrm{Y}$ & $\mathrm{Y}$ & $\mathrm{Y}$ & $\mathrm{Y}$ & $\mathrm{Y}$ & $\mathrm{Y}$ & $\mathrm{N}$ & $\mathrm{Y}$ & $\mathrm{N}$ & $\mathrm{Y}$ & UC & 8 \\
\hline Gao et al. [45] & $\mathrm{Y}$ & $\mathrm{Y}$ & $\mathrm{Y}$ & UC & $\mathrm{Y}$ & $\mathrm{Y}$ & $\mathrm{N}$ & $\mathrm{Y}$ & $\mathrm{N}$ & $\mathrm{N}$ & UC & 6 \\
\hline Gao et al. [46] & $\mathrm{Y}$ & $\mathrm{Y}$ & $\mathrm{Y}$ & UC & $\mathrm{N}$ & $\mathrm{Y}$ & $\mathrm{N}$ & $\mathrm{Y}$ & $\mathrm{N}$ & $\mathrm{N}$ & UC & 5 \\
\hline Li et al. [47] & $\mathrm{Y}$ & $\mathrm{Y}$ & $\mathrm{Y}$ & $\mathrm{UC}$ & $\mathrm{N}$ & $\mathrm{Y}$ & $\mathrm{N}$ & $\mathrm{Y}$ & $\mathrm{N}$ & $\mathrm{Y}$ & UC & 6 \\
\hline He et al. [48] & $\mathrm{Y}$ & $\mathrm{N}$ & $\mathrm{Y}$ & $\mathrm{UC}$ & $\mathrm{N}$ & $\mathrm{Y}$ & $\mathrm{N}$ & $\mathrm{N}$ & $\mathrm{N}$ & $\mathrm{Y}$ & $\mathrm{UC}$ & 4 \\
\hline Wang [49] & $\mathrm{Y}$ & $\mathrm{Y}$ & $\mathrm{Y}$ & $\mathrm{Y}$ & $\mathrm{Y}$ & $\mathrm{Y}$ & $\mathrm{N}$ & $\mathrm{Y}$ & $\mathrm{N}$ & $\mathrm{N}$ & $\mathrm{UC}$ & 7 \\
\hline Wang et al. [50] & $\mathrm{Y}$ & $\mathrm{Y}$ & $\mathrm{Y}$ & UC & $\mathrm{N}$ & $\mathrm{Y}$ & $\mathrm{N}$ & $\mathrm{Y}$ & $\mathrm{N}$ & $\mathrm{N}$ & UC & 5 \\
\hline Zhang et al. [51] & $\mathrm{Y}$ & $\mathrm{Y}$ & $\mathrm{Y}$ & $\mathrm{Y}$ & $\mathrm{N}$ & $\mathrm{Y}$ & $\mathrm{N}$ & $\mathrm{Y}$ & $\mathrm{N}$ & $\mathrm{Y}$ & UC & 7 \\
\hline He et al. [52] & $\mathrm{Y}$ & $\mathrm{Y}$ & $\mathrm{N}$ & UC & $\mathrm{Y}$ & $\mathrm{Y}$ & $\mathrm{N}$ & $\mathrm{N}$ & $\mathrm{N}$ & $\mathrm{N}$ & UC & 4 \\
\hline Wei [53] & $\mathrm{Y}$ & $\mathrm{Y}$ & $\mathrm{Y}$ & $\mathrm{Y}$ & $\mathrm{Y}$ & $\mathrm{Y}$ & $\mathrm{Y}$ & $\mathrm{Y}$ & $\mathrm{N}$ & $\mathrm{Y}$ & $\mathrm{Y}$ & 10 \\
\hline Che et al. [54] & $\mathrm{Y}$ & $\mathrm{Y}$ & $\mathrm{Y}$ & $\mathrm{Y}$ & $\mathrm{N}$ & $\mathrm{Y}$ & $\mathrm{N}$ & $\mathrm{Y}$ & $\mathrm{N}$ & $\mathrm{N}$ & UC & 6 \\
\hline Yu et al. [55] & $\mathrm{Y}$ & Y & $\mathrm{Y}$ & $\mathrm{Y}$ & $\mathrm{N}$ & $\mathrm{Y}$ & $\mathrm{N}$ & $\mathrm{Y}$ & $\mathrm{N}$ & $\mathrm{N}$ & UC & 6 \\
\hline Chen [56] & Y & Y & $\mathrm{Y}$ & $\mathrm{Y}$ & Y & $\mathrm{Y}$ & $\mathrm{N}$ & $\mathrm{Y}$ & $\mathrm{N}$ & Y & UC & 8 \\
\hline Chen et al. [57] & $\mathrm{Y}$ & $\mathrm{Y}$ & $\mathrm{Y}$ & $\mathrm{Y}$ & $\mathrm{N}$ & $\mathrm{Y}$ & $\mathrm{N}$ & $\mathrm{Y}$ & $\mathrm{N}$ & $\mathrm{Y}$ & UC & 7 \\
\hline Cui [58] & $\mathrm{Y}$ & $\mathrm{Y}$ & $\mathrm{Y}$ & UC & $\mathrm{N}$ & $\mathrm{Y}$ & $\mathrm{N}$ & $\mathrm{Y}$ & $\mathrm{N}$ & $\mathrm{Y}$ & UC & 6 \\
\hline $\mathrm{Gu}$ [59] & $\mathrm{Y}$ & $\mathrm{Y}$ & $\mathrm{Y}$ & $\mathrm{Y}$ & $\mathrm{Y}$ & $\mathrm{Y}$ & $\mathrm{N}$ & $\mathrm{Y}$ & $\mathrm{N}$ & $\mathrm{N}$ & UC & 7 \\
\hline Jiang [60] & $\mathrm{Y}$ & $\mathrm{Y}$ & $\mathrm{Y}$ & $\mathrm{Y}$ & $\mathrm{Y}$ & $\mathrm{Y}$ & $\mathrm{Y}$ & $\mathrm{Y}$ & $\mathrm{N}$ & $\mathrm{Y}$ & UC & 9 \\
\hline Wang et al. [61] & $\mathrm{Y}$ & $\mathrm{Y}$ & $\mathrm{Y}$ & $\mathrm{Y}$ & $\mathrm{Y}$ & $\mathrm{N}$ & $\mathrm{Y}$ & $\mathrm{N}$ & $\mathrm{N}$ & $\mathrm{N}$ & UC & 7 \\
\hline Farooq et al. [62] & $\mathrm{Y}$ & $\mathrm{Y}$ & $\mathrm{Y}$ & UC & $\mathrm{N}$ & $\mathrm{Y}$ & $\mathrm{N}$ & $\mathrm{N}$ & $\mathrm{N}$ & $\mathrm{Y}$ & UC & 6 \\
\hline Zhao et al. [63] & $\mathrm{Y}$ & $\mathrm{Y}$ & $\mathrm{Y}$ & $\mathrm{Y}$ & $\mathrm{Y}$ & $\mathrm{Y}$ & $\mathrm{Y}$ & $\mathrm{Y}$ & $\mathrm{N}$ & $\mathrm{Y}$ & UC & 9 \\
\hline Lin et al. [64] & $\mathrm{Y}$ & $\mathrm{Y}$ & $\mathrm{Y}$ & $\mathrm{Y}$ & $\mathrm{N}$ & $\mathrm{Y}$ & $\mathrm{N}$ & $\mathrm{Y}$ & $\mathrm{N}$ & $\mathrm{N}$ & $\mathrm{Y}$ & 7 \\
\hline Sun et al. [65] & $\mathrm{Y}$ & $\mathrm{Y}$ & $\mathrm{Y}$ & $\mathrm{UC}$ & $\mathrm{Y}$ & $\mathrm{Y}$ & $\mathrm{N}$ & $\mathrm{Y}$ & $\mathrm{N}$ & $\mathrm{N}$ & UC & 6 \\
\hline
\end{tabular}

$Y$ yes, $U C$ unclear, $N$ no, $A H R Q$ agency for health research and quality. $A H R Q$ checklist items 1 -Define the source of information, 2-List inclusion and exclusion criteria for exposed and unexposed subjects or refer to previous publications. 3-Indicate time period used for identifying patients. 4-Indicate whether or not subjects were consecutive if not population-based. 5-Indicate if evaluators of subjective components of study were masked to other aspects of the status of the participants. 6-Describe any assessments undertaken for quality assurance purposes. 7-Explain any patient exclusions from analysis. 8-Describe how confounding was assessed and/or controlled. 9-If applicable, explain how missing data were handled in the analysis. 10-Summarize patient response rates and completeness of data collection. 11-Clarify what follow-up, if any, was expected and the percentage of patients for which incomplete data or follow-up was obtained 
Table 5 The EQ-5D-3L value sets of five countries

\begin{tabular}{|c|c|c|c|c|c|}
\hline & Japan [71] & China [72] & UK [73] & Thailand [74] & USA [75] \\
\hline Constant & 0.152 & 0.039 & 0.081 & 0.202 & - \\
\hline MO2 & 0.075 & 0.099 & 0.069 & 0.121 & 0.146 \\
\hline $\mathrm{MO} 3$ & 0.418 & 0.246 & 0.314 & 0.432 & 0.558 \\
\hline $\mathrm{SC} 2$ & 0.054 & 0.105 & 0.104 & 0.121 & 0.175 \\
\hline $\mathrm{SC} 3$ & 0.102 & 0.208 & 0.214 & 0.242 & 0.471 \\
\hline UA2 & 0.044 & 0.074 & 0.036 & 0.059 & 0.140 \\
\hline UA3 & 0.133 & 0.193 & 0.094 & 0.118 & 0.374 \\
\hline PD2 & 0.080 & 0.092 & 0.123 & 0.072 & 0.173 \\
\hline PD3 & 0.194 & 0.236 & 0.386 & 0.209 & 0.537 \\
\hline AD2 & 0.063 & 0.086 & 0.071 & 0.032 & 0.156 \\
\hline AD3 & 0.112 & 0.205 & 0.236 & 0.110 & 0.450 \\
\hline N3 & - & 0.022 & 0.269 & 0.139 & - \\
\hline D1 & - & - & - & - & -0.140 \\
\hline$(\mathrm{I} 2)^{\wedge} 2$ & - & - & - & - & 0.011 \\
\hline (I3) & - & - & - & - & -0.122 \\
\hline$(\mathrm{I} 3)^{\wedge} 2$ & - & - & - & - & -0.015 \\
\hline Sample size & 621 & 1147 & 3395 & 1409 & 4048 \\
\hline States directly valued & 17 & 97 & 42 & 86 & 42 \\
\hline Valuation method & TTO & TTO & TTO & TTO & TTO \\
\hline Range & $(-0.111,0.804)$ & $(-0.149,0.961)$ & $(-0.594,0.883)$ & $(-0.452,0.766)$ & $(-0.102,0.860)$ \\
\hline
\end{tabular}

mo mobility, $S C$ self-care, $U A$ usual activities, $P D$ pain/discomfort, $A D$ anxiety/depression, $N 3$ any dimension is at level $3, D 1$ the number of dimension not at level 1, minus $1, I 2$ the number of dimension is level 2, minus $1,(I 2)^{\wedge} 2$ the square of I2, I3 the number of dimensions at level 3 , minus $1,(I 3)^{\wedge} 2$ the square of I3, TTO time trade-off

\section{Appendix}

See Tables 3, 4, 5 .

\section{References}

1. World Health Organization. Global Health Observatory (GHO) data, cause-specific mortality (2015). http://www.who.int/healt hinfo/global_burden_disease/estimates/en/index1.html. Accessed 23 May 2017.

2. International Diabetes Federation. IDF diabetes atlas seventh edition (2015). http://www.diabetesatlas.org/. Accessed 28 May 2017.

3. Center for Health Statistics and Information, Ministry of Health: An Analysis Report of National Health Services Survey in China (2013). http://www.moh.gov.cn/ewebeditor/uploadfile /2016/10/20161026163512679.pdf. Accesed 30 May 2017.

4. Center for Health Statistics and Information, Ministry of Health: An Analysis Report of National Health Services Survey in China (2008). http://www.moh.gov.cn/cmsresources/mohwsbwstjxxzx/ cmsrsdocument/doc9911.pdf. Accesed 30 May 2017.

5. Mathers, C. D., \& Loncar, D. (2006). Projections of global mortality and burden of disease from 2002 to 2030. PLoS Medicine, $3(11)$, e442.

6. Fang, X., Wang, X., \& Bai, C. (2011). COPD in China: The burden and importance of proper management. Chest, 139(4), 920-929.

7. WHO. (2013). A global brief on hypertension: Silent killer, global public health crisis: World Health Day, Geneva: WHO.
8. National Bureau of Statistics of People's Republic of China. (2016). Statistical communique of the People's Republic of china on the 2016 national economic and social development. http:// www.stats.gov.cn/tjsj/zxfb./201702/t20170228_1467424.html. Accesed 21 May 2017.

9. Ministry of Civil affairs of People's Republic of China. (2010). Statistical report of the People's Republic of china on the social services development in 2010. http://www.mca.gov.cn/article/ zwgk/mzyw/201106/20110600161364.shtml Accesed 21 May 2017.

10. Engel, G. L. (1977). The need for a new medical model: A challenge for biomedicine. Science, 196(4286), 129-136.

11. WHO. (1993). The development of the WHO quality of life assessment instrument. Geneva: WHO.

12. Räsänen, P., Roine, E., Sintonen, H., Semberg-Konttinen, V., Ryynänen, O. P., \& Roine, R. (2006). Use of quality-adjusted life years for the estimation of effectiveness of health care: A systematic literature review. International Journal of Technology Assessment in Health Care, 22(02), 235-241.

13. Guan, H. J., \& Liu, G. G. (2015). Comparison analysis on health relatedquality of life among urban and rural residents in 4 cities of China. Journal of Chinese Health Economics, 34(2), 5-12. (in Chinese).

14. Rabin, R., \& de Charro, F. (2001). EQ-5D: A measure of health status from the EuroQol Group. Annals of Medicine, 33, 337-343.

15. Horsman, J., Furlong, W., Feeny, D., \& Torrance, G. (2003). The Health Utilities Index (HUI): Concepts, measurement properties and applications. Health and Quality of Life Outcomes, 1, 54.

16. Brazier, J., Roberts, J., \& Deverill, M. (2002). The estimation of a preference-based measure of health from the SF-36. Journal of Health Economics, 21, 271-292. 
17. NICE. (2013). Guide to the methods of technology appraisal 2013. London: National institute of health and care excellence.

18. China Guidelines for Pharmacoeconomic Evaluations. (2011). http://www1.gsm.pku.edu.cn/UserFiles/File/543a4421-b610471b-bada-47d511160cfa.pdf. Accessed 9 Apr 2017.

19. Brooks, R. (1996). EuroQol: The current state of play. Journal of Health Policy, 37, 53-72.

20. Konerding, U., Elkhuizen, S. G., Faubel, R., Forte, P., Malmström, T., Pavi, E., \& Janssen, M. B. (2014). The validity of the EQ5D-3L items: An investigation with type 2 diabetes patients from six European countries. Health and Quality of Life Outcomes, 12(1), 181

21. Ellis, J. J., Eagle, K. A., Kline-Rogers, E. M., \& Erickson, S. R. (2005). Validation of the EQ-5D in patients with a history of acute coronary syndrome. Current Medical Research and Opinion, 21(8), 1209-1216.

22. Pickard, A. S., Wilke, C., Jung, E., Patel, S., Stavem, K., \& Lee, T. A. (2008). Use of a preference-based measure of health (EQ-5D) in COPD and asthma. Respiratory Medicine, 102(4), 519-536.

23. Wang, H. M., Patrick, D. L., Edwards, T. C., Skalicky, A. M., Zeng, H. Y., \& Gu, W. W. (2012). Validation of the EQ-5D in a general population sample in urban China. Quality of Life Research, 21(1), 155-160.

24. Wang, C., Kane, R. L., Xu, D., \& Meng, Q. (2015). Health literacy as a moderator of health-related quality of life responses to chronic disease among Chinese rural women. BMC Women's Health, 15(1), 34.

25. Moher, D., Liberati, A., Tetzlaff, J., \& Altman, D. G. (2009). The prisma group. Preferred reporting items for systematic reviews and meta-analyses: The PRISMA statement. PLoS Medicine, 6, e1000097.

26. Daar, A. S., Singer, P. A., Persad, D. L., Pramming, S. K., Matthews, D. R., Beaglehole, R., et al. (2007). Grand challenges in chronic non-communicable diseases. Nature, 450(7169), 494-496.

27. Rostom, A., Dubé, C., Cranney, A., Saloojee, N., Sy, R., Garritty, C. et al. (2004). Celiac disease. Rockville, MD: Agency for Healthcare Research and Quality (US).

28. Zhu, Y. C. (2013). Study on the model of taking oral antidiabetic drug and current situation of quality of life among type 2 diabetes patients. Hangzhou: Zhejiang University. (in Chinese).

29. Liang, M. M. (2014). Study on quality of life and influence factors among type 2 diabetes patients in community in Beijing. Beijing: Beijing University of Chinese Medicine. (in Chinese).

30. Luo, Y. J., Fang, Y., \& Ding, X. S. (2009). The quality of life of patients with type 2 diabetes measured by EQ-5D and its influential factors analysis. Chinese Journal of Pharmaceutical Economics, 2, 12-18. (in Chinese)

31. Tang, X. M., Yao, M. H., \& Chen, G. P. (2015). An evaluation of life quality among patients with diabetes mellitus in rural areas. Zhejiang Journal of Preventive Medecine, 27(5), 458-461. (in Chinese).

32. Han, Y. R., Wu, J., Cai, D. H. (2013). Evaluation of health-related quality of life in type 2 diabetic patients with various complications and oral drug treatment. Chinese Journal of Endocrinology and Metabolism, 29(8), 656-659. (in Chinese).

33. Chang, K. (2010). Comorbidities, quality of life and patients' willingness to pay for a cure for type 2 diabetes in Taiwan. Public Health, 124(5), 284-294.

34. Yan, B. P., Zhang, Y., Kong, A. P. S., Luk, A. O., Ozaki, R., Yeung, R., et al. (2015). Borderline ankle-brachial index is associated with increased prevalence of micro-and macrovascular complications in type 2 diabetes: A cross-sectional analysis of 12,772 patients from the Joint Asia Diabetes Evaluation Program. Diabetes and Vascular Disease Research, 12(5), 334-341.

35. Ji, L., Zou, D., Liu, L., Qian, L., Kadziola, Z., Babineaux, S., et al. (2015). Increasing body mass index identifies Chinese patients with type 2 diabetes mellitus at risk of poor outcomes. Journal of Diabetes and Its Complications, 29(4), 488-496.

36. Zhu, Y. C., Wang, Y., \& Li, H. (2016). A study on effects of various chronic diseases on quality of life. Zhejiang Journal of Preventive Medicine, 28(1), 24-27. (in Chinese).

37. Cao, Y., Tang, X., Yang, L., Li, N., Wu, Y. Q., Fan, W. Y., et al. (2012). Influence of chronic diseases on health related quality of life in middle-aged and elderly people from rural communities: Application of EQ-SD scale on a Health Survey in Fangshan, Beijing. Chinese Journal of Epidemiology, 14(8), 17-22. (in Chinese).

38. Xiong, Q. M., Zhou, Q. Q., Liu, Y. (2014). Assessing quality of life among patients with coronary heart disease. Journal of Clinical Cardiology, 30(1), 27-30. (in Chinese).

39. Wang, L., Wu, Y. Q., Tang, X., Li, N., He, L., Cao, Y., et al. (2015). Profile and correlates of health-related quality of life in Chinese patients with coronary heart disease. Chinese Medical Journal, 128(14), 1853.

40. Wu, J., Han, Y., Zhao, F. L., Zhou, J., Chen, Z., \& Sun, H. (2014). Validation and comparison of EuroQoL-5 dimension (EQ-5D) and Short Form-6 dimension (SF-6D) among stable angina patients. Health and Quality of Life Outcomes, 12(1), 156.

41. Wu, J., Han, Y., Xu, J., Lu, Y., Cong, H., Zheng, J., \& Sun, H. (2014). Chronic stable angina is associated with lower healthrelated quality of life: Evidence from Chinese patients. PLoS ONE, 9(5), e97294.

42. Wu, M., Zhao, Q., Chen, Y., Fu, C., \& Xu, B. (2015). Quality of life and its association with direct medical costs for COPD in urban China. Health and Quality of Life Outcomes, 13(1), 57.

43. Chen, J., Wong, C. K. H., McGhee, S. M., Pang, P. K., \& Yu, W. C. (2014). A comparison between the EQ-5D and the SF-6D in patients with chronic obstructive pulmonary disease (COPD). PLOS ONE, 9(11), e112389.

44. Ding, B., Small, M., Bergström, G., \& Holmgren, U. (2017). A cross-sectional survey of night-time symptoms and impact of sleep disturbance on symptoms and health status in patients with COPD. International Journal of Chronic Obstructive Pulmonary Disease, 12, 589-599.

45. Gao, L., Xia, L., Pan, S. Q., Xiong, T., \& Li, S. C. (2013). Validation of a Chinese version of the Quality of Well-Being ScaleSelf-Administered (QWB-SA) in patients with epilepsy. Epilepsia, 54(9), 1647-1657.

46. Gao, L., Xia, L., Pan, S. Q., Xiong, T., \& Li, S. C. (2014). Psychometric properties of Chinese language Liverpool Seizure Severity Scale 2.0 (LSSS 2.0) and status and determinants of seizure severity for patients with epilepsy in China. Epilepsy \& Behavior, 31, 187-193.

47. Li, Y., Dong, Z. H., \& Sun, L. H. (2014). Investigation and analysis of the effects of community management of hypertension patients on quality of life. China Pharmaceutical, 25(12), 1080-1083. (in Chinese).

48. He, M. M., Fan, C. S., Zeng, G., et al. (2013). Relativity analysis between the medicine compliance and life quality of patients with hypertension in Beijing. Chinese Primary Health Care, 27(3), 57-58. (in Chinese).

49. Wang, X. H. (2017). Assessing life quality for patients with hypertension in lianyungang rural regions based on EQ-5D. Hefei: Anhui Medical University. (in Chinese).

50. Wang, Y., Guan, X., Zang, Y. J. (2017). Evaluation of quality of life for urban middle-aged and elderly hypertensive patients. Journal of Preventive Medicine and Public Health, 28(4), 137-140. (in Chinese).

51. Zhang, L., Guo, X., Zhang, J., Chen, X., Zhou, C., Ge, D., et al. (2017). Health-related quality of life among adults with and without hypertension: A population-based survey using EQ-5D in Shandong, China. Scientific Reports, 7(1), 14960. 
52. He, Y. L., Guo, Q., \& Qu, Q. M. (2016). The study of quality of life of patients with cerebral infarction in rural areas of Baoji city. World Clinics Medical, 10(24), 242-243. (in Chinese).

53. Wei, X. (2013). Study of the relationship of the different blood pressure types and ambulatory arterial stiffness index with the early severity in acute cerebral infarction patients. Nanning: Guangxi Medical University. (in Chinese).

54. Che, Y. H., You, J., Chongsuvivatwong, V., Li, L., Sriplung, H., Yan, Y. Z., et al. (2013). Dynamics and liver disease specific aspects of quality of life among patients with chronic liver disease in Yunnan, China. Asian Pacific Journal of Cancer Prevention, 15(12), 4765-4771.

55. Yu, Q., Fan, X. L., Zhang, X., et al. (2016). Evaluation on life quality utility weight of hepatitis B patients with different disease status. Chinese Journal of Health Economics, 35(6), 68-70. (in Chinese).

56. Chen, S. T. (2016). Research on the economic burden and quality of life of patients with lung cancer. Hefei: Anhui Medical University. (in Chinese).

57. Chen, S. T., Chen, J. J., Wang, L. D. (2016). The study of health related quality of life of patients with esophagus cancerJ. Acta Universitatis Medicinalis Nanjing (Social Science), 72(1), 24-28. (in Chinese).

58. Cui, W. (2014). Evaluation of Hebei province to investigate the quality of life and economic burden in children with cerebral palsy. Changchun: Jilin University. (in Chinese).

59. Gu, J. (2009). A comparison between methods of assessing utility values in rheumatoid arthritis. Shanghai: Fudan University. (in Chinese).

60. Jiang, F. (2016). Effect of sarcopenia on bone mineral density and health-related quality of life in older men. Jinan: Shandong University. (in Chinese).

61. Wang, K. L., Wu, C. H., Huang, C. C., Wu, T. C., Naditch-Brûlé, L., Steg, P. G. et al. (2014). Complexity of atrial fibrillation patients and management in Chinese ethnicity in routine daily practice: Insights from the RealiseAF Taiwanese cohort. Journal of Cardiology, 64(3), 211-217.

62. Farooq, U., Guo, X., Chuang, L. H., Fang, H., Zhuang, G., \& Xia, C. (2011). Measuring health-related quality of life in Kashin-Beck disease using EQ-5D. Quality of Life Research, 20(3), 425-429.

63. Zhao, F., Yue, M., Yang, H., Wang, T., Wu, J. H., \& Li, S. C. (2010). Validation and comparison of EuroQol and short form 6D in chronic prostatitis patients. Value Health, 13(5), 649-656.

64. Lin, J. C., \& Yu, J. H. (2012). Assessment of quality of life among Taiwanese patients with visual impairment. Journal of the Formosan Medical Association, 111(10), 572-579.

65. Sun, J., Zhao, Y., Yang, R., Guan, T., Iorio, A., Chinese HERO study group, et al. (2017). The demographics, treatment characteristics and quality of life of adult people with haemophilia in China-results from the HERO study. Haemophilia, 23(1), 89-97.

66. Abdin, E., Subramaniam, M., Vaingankar, J. A., Luo, N., \& Chong, S. A. (2013). Measuring health-related quality of life among adults in Singapore: Population norms for the EQ-5D. Quality of Life Research, 22(10), 2983-2991.

67. Solli, O., Stavem, K., \& Kristiansen, I. S. (2010). Health-related quality of life in diabetes: The associations of complications with EQ-5D scores. Health and Quality of Life Outcomes, 8(1), 18.
68. Liu, Y., Long, H., Chen, Y., Wang, J., Li, Y., Li, Y. et al. (2016). Progress of research on urban-rural transformation and rural development in China in the past decade and future prospects. Journal of Geographical Sciences, 26(8), 1117-1132.

69. National Bureau of Statistics of the People's Republic of China. (2015). Statistical bulletin of national economic and social development. Accessed Apr 22, 2018, from http://www.stats.gov.cn/ tjsj/zxfb/201602/t20160229_1323991.html.

70. Su, M., Zhou, Z., Si, Y., Wei, X., Xu, Y., Fan, X., et al. (2018). Comparing the effects of China's three basic health insurance schemes on the equity of health-related quality of life: Using the method of coarsened exact matching. Health and Quality of Life Outcomes, 16(1), 41.

71. Tsuchiya, A., Ikeda, S., Ikegami, N., Nishimura, S., Sakai, I., Fukuda, T. et al. (2002). Estimating an EQ-5D population value set: The case of Japan. Health Economy, 11(4), 341-353.

72. Liu, G. G., Wu, H. Y., Li, M. H., Gao, C., \& Luo, N. (2014). Chinese time trade-off values for EQ-5D health states. Value Health, 17(5), 597-604.

73. Dolan, P. (1996). Modelling valuations for health states: The effect of duration. Health Policy, 38(3), 189-203.

74. Tongsiri, S., \& Cairns, J. (2011). Estimating population-based values for EQ-5D health states in Thailand. Value Health, 14(8), $1142-1145$.

75. Shaw, J. W., Johnson, J. A., \& Coons, S. J. (2005). US Valuation of the EQ-5D health states: Development and testing of the D1 Valuation Model. Medical Care, 43(3), 203.

76. Herdman, M., Gudex, C., Lloyd, A.,, Janssen, M. F., Kind, P., Parkin, D. et al. (2011). Development and preliminary testing of the new five-level version of EQ-5D (EQ-5D-5L). Quality of life Research, 20(10), 1727-1736.

77. van Agt, H., \& Bonsel, G. (2015). The number of levels in the descriptive system: EQ-5D concepts and methods: A developmental history (pp. 29-33). New York: Springer.

78. Luo, N., Liu, G., Li, M., Guan, H., Jin, X., \& Rand-Hendriksen, K. (2017). Estimating an EQ-5D-5L value set for China. Value Health, 20(4), 662-669.

79. Koopmanschap, M. (2002). Coping with Type II diabetes: The patient's perspective. Diabetologia, 45(7), S18-S22.

80. Clarke, P. M., Hayes, A. J., Glasziou, P. G., Scott, R., Simes, J., \& Keech, A. C. (2009). Using the EQ-5D index score as a predictor of outcomes in patients with type 2 diabetes. Medical Care, 47(1), 61-68.

81. Dyer, M. T., Goldsmith, K. A., Sharples, L. S., \& Buxton, M. J. (2010). A review of health utilities using the EQ-5D in studies of cardiovascular disease.. Health and Quality of Life Outcomes, $8(1), 13-13$

82. Moayeri, F., Hsueh, Y. S., Clarke, P., Hua, X., \& Dunt, D. (2016). Health state utility value in chronic obstructive pulmonary disease (COPD); The challenge of heterogeneity: A systematic review and meta-analysisJ. COPD-Journal of Chronic Obstructive Pulmonary Disease, 13(3), 380-398. 